\title{
Online Review Helpfulness: Impact of Reviewer Profile Image
}

\author{
Sahar Karimi, $\mathrm{PhD}^{1}$ \\ Edge Hill University, Business School \\ St Helens Rd, Ormskirk, Lancashire L39 4QP, U.K \\ Karimis@edgehill.ac.uk \\ Fang Wang, $\mathrm{PhD}$ \\ Wilfrid Laurier University, Lazaridis School of Business \& Economics \\ 75 University Avenue West, Waterloo, Ontario, Canada N2L 3C5 \\ fwang@wlu.ca
}

\begin{abstract}
Despite the growing number of studies on online reviews, the impact of visual cues on consumer's evaluation of review helpfulness has remained underexplored. It is not yet known whether and how images influence the way online reviews are perceived. This paper introduces and empirically examines the potential effects of reviewer profile image, a photo/image displayed next to the reviewer name, on review helpfulness by drawing on the decorative and information functions of images. With a sample of 2,178 reviews from mobile gaming applications, we report that reviewer profile image can significantly enhance consumer's evaluation of review helpfulness; whereas there is no differential effect among image types (i.e. self, family, or random images). Interestingly, the effect of reviewer profile image on review helpfulness is moderated by review length, but not review valence and equivocality. Results suggest that reviewer profile image enhances the perception of review helpfulness by serving mainly as a visual decoration that creates affective responses rather than identity information.
\end{abstract}

Keywords: online reviews, review helpfulness, reviewer image, reviewer profile image, identity information, decorative images

\footnotetext{
${ }^{1}$ Corresponding Author: Karimis@edgehill.ac.uk, +44 7809474560
} 


\section{Online Review Helpfulness: Impact of Reviewer Profile Image}

\section{Introduction}

Consumers' dependence on the opinions of others when making purchase decisions $[29,65]$ has led to proliferation of online review platforms. Online reviews have turned into a valuable information source that affects consumer choices. Their influence on consumer purchase intention [39], product choice [22], and sales [6, 8, 11, 13, 61, 65] has been well documented in the literature. However, online reviews are not equal in their value to consumers. Consumers look for reviews that can assist them in their decision making. Whether a review contributes to product evaluation and purchase decision, in other words its utility or diagnosticity, is commonly measured by the review "helpfulness" [14, 24, 31, 34, 37, 42, 63]. Consumers are more receptive to and influenced by reviews that are perceived to be more helpful [66]. Websites that identify and indicate helpful reviews achieve higher consumer attention and stickiness [63]. Businesses search for practices that facilitate generation of helpful reviews on their e-commerce or review site in order to enhance its value to users [28]. Therefore, understanding attributes and indicators of helpful reviews and promoting such reviews are essential.

Existing research has identified several review and reviewer attributes that influence review helpfulness [23, 28, 37, 40, 63]. Common review attributes examined include review length, rating valence, and review equivocality/extremity [3, 16, 34, 37, 43]. Reviewer attributes studied in the literature include reviewer innovativeness [37], reviewer identity disclosure [16, 43], reviewer expertise and reputation [43]. While the IS literature has long recognized the importance of images in online environment $[9,10]$, studies of online review helpfulness have largely overlooked the role of reviewer profile images. No research has systematically examined the impact of this potentially influential visual component. 
Reviewer profile image is a photo displayed next to the user name on review platforms. With its effect unproven, there are diverse practices in displaying the reviewer profile image. Some websites, such as amazon.com, do not display reviewer profile images. A number of websites, such as Google Play, allow users to upload an image of their choice if they wish so, and show a standard profile image when users do not provide a personal one. Others, such as tripadvisor.com not only allow users to upload their own images, but also force into place a randomly selected image when users do not upload any. Despite the efforts invested in facilitating increase of helpful reviews [28], there is no evidence that suggests one practice is more advantageous over the others. The impact of reviewer profile image on online review helpfulness has remained largely underexplored [28].

This study takes the literature forward by examining whether and how reviewer profile images influence consumer perception of review helpfulness. It considers two functions for reviewer profile image that affect perceived review helpfulness, using visual appeal and source identity disclosure concepts. As an important, and in most cases the only visual component embedded in online reviews, reviewer profile image has a visual appeal that adds to the value of review content by drawing readers' attention and creating affective responses $[10,50,51]$. Thus, availability of a reviewer profile image may enhance the perceived helpfulness of a review. This effect pertains to all types of images. In addition, a specific type of image, reviewer self-image (their real photo) provides identity information about them that can further increase review helpfulness [16, 43]. For example, two studies $[16,43]$ consider reviewer self-image as a part of identity information that is revealed to readers. However, the overall impact of reviewer profile image and its multifaceted functions affecting review helpfulness have not been systematically examined. The narrow focus on one type of images (self-image) as reviewer identity information, has limited our understanding of the impact of reviewer profile image. Reviewer profile images serve other functions beyond revealing identity information. Additionally, a large portion of images uploaded by users is not self-images. By 
considering both decorative and information functions of reviewer profile image, we examine its impact in a boarder context and explore the difference among various types of images.

A sample of 2,178 online reviews from nine gaming apps is collected. The effect of reviewer profile image on review helpfulness is explored along with previously established review attributes (i.e. review length, rating valence, and equivocality). This research adds to the empirical studies on review helpfulness [14] and offers several distinct contributions. We introduce and validate a new attribute, reviewer profile image, as an important determinant of review helpfulness. We show that the effect of reviewer profile image is moderated by review length, but not review valence and equivocality. Drawing on information systems, marketing and individual learning literatures, we conceptualize two main functions for reviewer profile image (i.e. information function and decorative function) in order to explain the nature of its impact on review helpfulness. Contradictory to extant research that considers self-image as a reviewer identity information, our results suggest that reviewer profile image enhances the perception of review helpfulness mainly through its decorative function. In light of our results, review sites that do not allow users to upload an image could re-consider and re-design their features to enhance user experience.

This study also diverges from previous research by using a different data source, Google Play. Earlier studies are predominantly based on reviews published on amazon.com. Mobile gaming applications are a fast growing market with estimated value above US\$50 billion in 2013 [19]. We draw the attention towards this important market as it is highly influenced by online reviews and electronic word-of-mouth (e-WOM). In addition, using a different data source is essential to validate and generalize previous findings on review attributes such as review depth, valence and equivocality.

The structure of the paper is as follows. Section 2 discusses the literature on online review helpfulness, introduces two functions of reviewer profile image and presents our research framework. Section 3 explains the research method and sampling strategy. It is followed by data analysis in section 4, which presents the results of hypothesis testing and discusses the findings. It is followed by 
a conclusion, theoretical and managerial implications, and discussion of limitations and further research in section 5 .

\section{Theoretical framework}

Review helpfulness defines the perceived value of a review to its readers and measures consumer's evaluation of a review [34]. It illustrates the degree to which a review contributes to a purchase decision by determining the level of its adoption by potential customers $[5,43]$. An increasing number of studies have explored factors that influence online review helpfulness. These factors include a relatively standard set of review attributes, such as review length, rating valence and review equivocality/extremity, and a diverse range of reviewer attributes, such as reviewer identity disclosure, reviewer expertise and reputation, reviewer innovativeness, reviewer online attractiveness and impact. Table 1 summarizes the key empirical studies and shows a comparison between them and this research.

\section{[Insert Table 1 Here]}

The WOM and information adoption literature emphasizes the importance of both message and message source characteristics in evaluation of message helpfulness [7, 33]. Similarly understanding the impact of both review (message) and reviewer (message source) attributes on the perception of review helpfulness is crucial. Consumers are influenced by both types of attributes when deciding which reviews to consider and which to reject [28]. While considering both, this research focuses mainly on a reviewer attribute; more specifically, it examines the effect of reviewer profile image on review helpfulness.

In an online review platform, a reviewer profile image may be displayed next to the review content. Presence of a reviewer profile image may have a profound impact on consumers' interpretation and comprehension of review content, thus influencing their perception of review helpfulness. For example, images can draw readers' attention and create affective responses [10, 30, 
50, 51]. A particular type of reviewer profile image, self-image, also provides reviewer identity information [16]. The way that reviewer profile images influence readers and different functions that these visual components serve when presented next to the review text have not been previously explored. This research examines the effect of reviewer profile image and image type on review helpfulness. The potential interaction between review attributes and reviewer profile image is also examined. Figure 1 presents our research framework.

\section{[Insert Figure 1 Here]}

\subsection{Reviewer profile image as a reviewer attribute}

It is long known that combining texts and images has a positive impact on readers' comprehension of the content [30]. When an image is presented besides the text, readers integrate pictorial and textual information by distributing their attention between them [44]. It is therefore important to understand how images and textual information affect and interact with each other [55].

Psychology and individual learning literature suggests that images serve two main functions when accompanied with a text: providing information (i.e. the information function) and generating affective responses through aesthetic appeal (i.e. the decorative function) [30, 53]. Applying this concept to the online review context, we consider the potential effect of reviewer profile image from two perspectives: 1) its decorative function that may attract readers' attention and create emotional and affective interests towards certain reviews, and 2) its information function that can provide reviewer identity information. The first function applies to all types of images and the second is associated with the presence of reviewer self-images.

\subsubsection{The decorative function of reviewer profile image}

Reviewers' images are the main visual elements embedded within the text-intensive review platforms. While being irrelevant to the content of the review, the reviewer profile image can create aesthetic appeal and a general impression in readers [55]. This is referred to as the decorative 
function of an image when images are barely aesthetically appealing. The decorative function of reviewer profile image may affect readers by drawing their attention and creating emotional and affective interests towards certain reviews $[48,30]$.

When an image is displayed in a textual environment, readers tend to glimpse at the image before reading the content $[55,56]$. Research on visual information seeking suggests that images direct the attention to certain places and change the perception of what is worth looking at $[51,57]$. One's attention is not equally directed to different sections of the environment, but it is affected by the salience of sections. Salience can be generated through contrast with local surrounding and using visual features such as colors [36] and images. In the text-intensive online review environment, the presence of reviewer profile image can add to the salience of a review, drawing readers' attention and signaling what is important to read.

In addition to directing reader's attention, decorative images influence readers by creating emotional and affective responses in them. Affective responses in readers can influence their perception of review helpfulness by enhancing ease of reading and comprehension of review content [30] and signaling social presence of the reviewer $[9,18]$. Presence of a decorative image can generate a better mood, alertness and calmness in readers [30]. Higher alertness and calmness can affect cognitive processing and reaction to the content. Therefore, images embedded in a message can enhance communication of its content to readers [50, 52]. For example, marketing research has found that images in an advertising message add to its aesthetic value and arouse affective responses in consumers that improves the communication capabilities of the message [46, 50]. Research on web design also reports that decorative images can improve websites' aesthetics and create emotional responses in users, resulting in a higher level of trust, [9] increased joy [10, 17] and alteration of information processing behaviour [50]. Studies of learning environment indicate that the decorative images reduce the perceived difficulty of learning materials [30]. Similarly, a reviewer profile image, 
as a decorative image, offers aesthetic value to the plain review text. The additional aesthetic value and its emotional outcomes can enhance communication and comprehension of review content, hence higher perceived helpfulness.

Moreover, presence of an image next to a text leads to affective responses in readers by signaling the social presence of reviewer to viewers. Social presence refers to the extent to which a medium allows users to experience others as being psychologically present [18]. Based on this theory, richness of the media creates psychological connection with users through implying a feeling or sense of warmth, sociability and human contact $[9,60,64]$. Images in the online environment convey a higher level of social presence compared to text $[9,18]$ and create interpersonal attraction among unacquainted online community members [59]. This psychological connection created through images reduces the criticality of users when evaluating the communicated message and affects their perception of the message content [10]. It also contributes to the way people relate to the experience of others $[12,20]$ and find their judgement relevant. Therefore, display of a reviewer profile image can enhance the feeling of social presence and psychological connection with the reviewer compared with a reviewer without an image. This leads to higher perceived credibility and helpfulness of review content.

\subsubsection{The information function of reviewer profile image}

The information function of an image suggests that images can contain useful information. Images are information in symbolic form [50] and are processed along with the text $[30,55]$. In the absence of verbal cues in online environment, message receivers use all pieces of information available to them to create an understanding of the message $[54,59]$. Reviewer profile image can provide additional information along with the review content. Among various types of images, reviewer self-image provides identity information $[16,43]$. 
Display of a personal image (self-image) next to the review text can provide additional information to the overall review content by revealing the identity of the reviewer [43]. The IS literature suggests that communication of identity information between individuals could enhance efficient information acquisition and relationship building [32]. In the online environment where information source is often unknown, disclosure of information source identity can increase information credibility [16], reduce customer uncertainty [54], and create bond and social attraction among members [45]. It can significantly influence the degree of information contribution in an online community [32]. Therefore, as an identity information, reviewer self-image may positively influence the perception of review helpfulness.

Several studies have examined the influence of reviewer identity disclosure on the perception of online review helpfulness, reaching inconsistent conclusions. Some [16] found that disclosure of reviewer identity can increase review credibility and therefore review helpfulness, while others [1, 43] did not find a significant impact. Among these studies, two [16, 43] considered availability of reviewer's real photo as a component of reviewer identity information.

Reviewers can upload any chosen image, however, disclosure of reviewer identity only applies to self-image. In other words, all images have a decorative function, while reviewer selfimage provides additional information function. This implies a differential effect between reviewer self-image and other types of image. As a result, reviewer self-image may have a stronger effect on review helpfulness compared with other types of images. We test the following:

H1(a). Availability of reviewer profile image has a positive effect on review helpfulness.

H1(b). The effect of reviewer profile image on review helpfulness is differential across various types of images. Compared with other types, reviewer self-image has a stronger effect on review helpfulness. 


\subsection{Review attributes and their interaction with reviewer profile image}

Three commonly examined review attributes that influence review helpfulness are review length, rating valence, and review equivocality/extremity (Table 1). Therefore, we control for these review attributes when examining the impact of reviewer profile image on review helpfulness and explore their potential moderating effect. We suggest that reviewer profile image may interact with review attributes, resulting in a stronger effect on review helpfulness in certain configurations of review attributes.

\subsubsection{Review length}

Review length or depth is defined as the length of information provided in a review. More detailed reviews are more diagnostic and therefore more useful in a decision-making situation [25]. These reviews assist consumers with their decisions by decreasing the decision uncertainty. Prior research suggests that review length enhances the information diagnosticity and review helpfulness by offering explanation and textual information $[1,6,34,43]$ and signaling higher quality reviews as the length implies higher level of effort invested by the reviewer $[4,16]$.

Review length may moderate the effect of reviewer profile image on review helpfulness. Reading longer reviews require more intensive information processing and cognitive effort, thus increasing the reading difficulty. Some readers do not read all the textual information when the text is long [44]. Images, serving a decorative function, can have a positive effect on readers' motivation and interest to continue reading [30]. They can also create positive emotions that enhance cognitive abilities and lead to successful information processing when the task is complex [49]. Studies on learning environment have found that decorative images can reduce the perceived difficulty of the content [30]. Therefore, review length may moderate the effect of reviewer profile image on review 
helpfulness. We expect the impact of reviewer profile image to be stronger for longer reviews due to their higher level of reading difficulty and cognitive effort needed. We test:

H2(a). Review length moderates the effect of reviewer profile image on review helpfulness. The effect of reviewer profile image on review helpfulness is stronger for longer reviews than shorter ones.

\subsubsection{Review valence}

Online reviews are often associated with an overall rating. Review valence (star rating, usually ranging from 1 to 5) is the evaluative direction of a review [40]. It refers to the positive, negative or neutral value associated with the review content $[6,11,15]$. Rating valence affects review helpfulness, but previous studies have suggested inconsistent results for the nature of this relationship [28]. Pan and Zhang [37] have reported a significantly positive relationship between valence and review helpfulness; whereas Racherla and Freiske [43] found this relationship to be significantly negative. Some studies (i.e. [6]) have found evidence of confirmatory bias suggesting that consumers look for reviews that affirm their decision. Others have reported evidence of negativity bias [8], which emphasizes the importance of negative reviews compared to positive ones.

Review valence may interact with the effect of reviewer profile image on review helpfulness. Psychology and WOM literature suggests that people are drawn to and put more emphasis on negative information compared to positive one [27]. Negative information is often given greater weight in decisions and negative reviews tend to be more influential [2, 6, 38]. Positive reviews, on the other hand, receive less attention and readers tend to quickly scan through them without fully comprehending the embedded information. Therefore, reviewer profile image may enhance the diagnosticity of positive reviews by attracting reader's attention and evoking interest in the content. We test: 
H2(b). Review valence moderates the effect of reviewer profile image on review helpfulness. The effect of reviewer profile image on review helpfulness is stronger for reviews of higher valence than those of lower valence.

\subsubsection{Review equivocality}

Review equivocality differentiates extreme and moderate reviews. A very low rating (i.e., one-star in the scale of 1-5 stars) or a very high rating (five-star) reflects review extremity; while a three-star rating is considered to be equivocal. An equivocal rating could either reflect a truly moderate review (indifference), or a series of positive and negative comments that cancel each other out (ambivalence) [34]. The relative diagnosticity or helpfulness of extreme versus moderate reviews has been empirically tested. Forman, Ghose and Wiesenfeld [16] have reported a negative relationship between review equivocality and helpfulness. Equivocal reviews are less informative as they contain unclear information and provide limited guidance to readers in their decision making.

The impact of review equivocality on review helpfulness could interact with reviewer profile image. Equivocal reviews attract less attention as they are less informative compared to their counterparts. Reviewer profile image in this condition might draw attention to and points out the importance of such reviews, enhancing their perceived helpfulness. Equivocal reviews represent indifferent or ambivalent opinions, being more difficult to process and interpret. Therefore, reviewer profile image, due to its decorative function, may motivate reading and reduce the difficulty of information processing [30]. We suggest that the impact of reviewer profile image is stronger for equivocal reviews. We test:

H2(c). Review equivocality moderates the effect of reviewer profile image on review helpfulness. The effect of reviewer profile image on review helpfulness is stronger for equivocal reviews. 


\section{Research method}

For the purpose of this research, online reviews of mobile gaming applications from Google Play (http://play.google.com) were collected. Google Play is a central application platform for the Android operating system, where consumers can discover, evaluate, purchase/download and review mobile applications. The single pool of reviews on Google Play plays a vital role in consumer decision making when purchasing or downloading gaming apps [58].

To ensure review quality, Google Play requires users to register and download the app before a review can be posted. App reviews are located under the app description and can be displayed based on their helpfulness, rating or posting date. Reviews consist of reviewer information such as reviewer name and image, review date, review content, and rating. When the reviewer profile image is not available, a standard user profile picture is presented. Figure 2 shows a screen shot of reviews at Google Play. After reading a review, users can choose to vote whether it is helpful. Based on user votes, Google Play ranks the helpfulness of a review.

\section{[Insert Figure 2 Here]}

Nine games were randomly selected as our data source, namely Candy Crush Sage, Crazy Craft 3 for Minecraft, Diamond Digger, FIFA 15 Ultimate Team, Invisible Skins for Slitherio, Minecraft, NBA 2K16, PAW Patrol: Rescue Run HD, and Teeny Titans (see Table 2). The sample represents a variety of mobile gaming apps in terms of their popularity, average rating, number of total reviews and price. To collect a representative sample from the large number of posted reviews, we started from the most helpful one and collected every 5th review based on their helpfulness ranking to the end, or until three hundred (300) reviews from each application were collected (representing its 1,500 most helpful reviews). This was done to ensure a sample with meaningful helpfulness ranking, i.e. reviews that are actually read and evaluated by consumers. Readers do not read all reviews, but only a limited number of them. When a large number of reviews are available, many are left unnoticed. As suggested by Cao, Duan and Gan [3], reviews with the helpfulness 
ranking below a certain number are not consulted and evaluated by readers and therefore, their ranking order may not indicate differences in review helpfulness. When a large number of reviews were available for an app, we collected data representing its 1,500 most helpful reviews because (1) 1,500 reviews provide a rich and sufficient review depository for readers to satisfy their information need; and (2) the significant data quality deterioration, often observed between the 1,300th and 1,500th helpful reviews, makes the legitimacy of helpfulness ranking for data beyond the top 1,500 helpful reviews a realistic concern. As Candy Crush Sage was by far the most popular game and had a much higher number of installations and reviews compared to others, 500 reviews from this application were collected (representing its 2,500 most helpful reviews). A total of 2,178 reviews were collected for the analysis. The gathered data for each review instance included: the review helpfulness rank, review rating, review date, review content, reviewer name, gender, availability and type of reviewer profile image.

\section{[Insert Table 2 Here]}

To test hypotheses H1(a) (i.e. the impact of reviewer profile image on review helpfulness), we examine the following:

$$
\begin{aligned}
\text { LnHelp }_{i p}=C & +\alpha_{1} \cdot \text { Image }_{i p}+\beta_{1} \cdot \text { LnLength }_{i p}+\beta_{2} \cdot \text { LnRating }_{i p}+\beta_{3} \cdot \text { Equivocality }_{i p} \\
& +\beta_{4} \cdot \text { LnAverage }_{p}+\beta_{5} \cdot \text { LnReview }_{p}+\beta_{6} \cdot \text { Gender }_{i p}+\beta_{7} \cdot \text { Name }_{i p}+\varepsilon_{i p}
\end{aligned}
$$

where $\mathrm{Help}_{\text {ip }}$ is the helpfulness ranking of review $\mathrm{i}$ for product $\mathrm{p}$ (a reverse measure of review helpfulness with the value of 1 indicating the most helpful review), Image $_{i p}$ represents the availability of reviewer profile image with the value of 1 for reviews with reviewer profile image and 0 otherwise, Length $_{i p}$ is the review length measured by its word count, Rating $_{i p}$ is the review rating valence, Equivocality Ep $_{\text {is }}$ the review equivocality with the value of 1 for reviews of rating 3 and 0 otherwise, Average $_{p}$ is the average rating of an application, Review $w_{p}$ is the total number of reviews

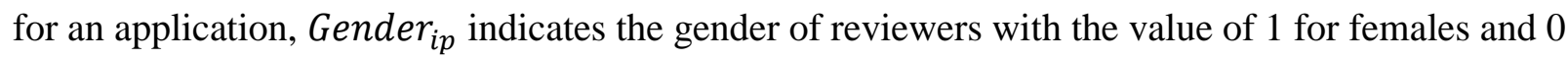


for males, and Name $i p$ presents the use of legitimate names by reviewers with the value of 1 for use of legitimate names and 0 otherwise. Average And $_{p}$ aview $p$ are control variables to control for product/application specific factors. Gender ${ }_{i p}$ and Name $_{i p}$ are control variables to control for reviewer specific factors. A logarithmic transformation is applied to variables Help ip $_{\text {Length }}$,

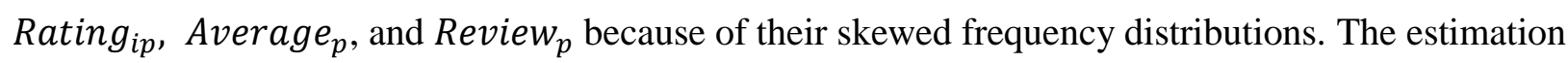
of $\alpha_{1}$ is used to evaluate $\mathrm{H} 1(\mathrm{a})$.

We observed that there are three types of images commonly posted by reviewers: self-image, family-image, and other images. Self-image is the photo of a person who can potentially be the reviewer. Family images contain a few people without any particular emphasis on one person; it can be assumed that the reviewer is in the photo with his/her family or friends. Other images include a wide variety of images such as a scenery, an object, a cartoon character and so on. To test H1(b) (i.e. the differential effect of different types of reviewer profile image on review helpfulness), we examine:

$$
\begin{aligned}
\text { LnHelp }_{i p}=C & +\alpha_{1} \cdot \text { Image }_{i p}+\alpha_{2} \cdot \text { SelfImage }_{i p}+\alpha_{3} \cdot \text { FamilyImage }_{i p}+\beta_{1} \\
& \cdot \text { LnLength }_{i p}+\beta_{2} \cdot \text { LnRating }_{i p}+\beta_{3} \cdot \text { Equivocality }_{i p}+\beta_{4} \cdot \text { LnAverage }_{p} \\
& +\beta_{5} \cdot \text { LnReview }_{p}+\beta_{6} \cdot \text { Gender }_{i p}+\beta_{7} \cdot \text { Name }_{i p}+\varepsilon_{i p}
\end{aligned}
$$

where SelfImage $e_{i p}$ indicates the availability of reviewer self-image with the value of 1 for reviews with reviewer self-image and 0 otherwise, and FamilyImage $e_{i p}$ shows the availability of a family image with the value of 1 for reviews with reviewer family image and 0 otherwise. The estimations of $\alpha_{2}$ and $\alpha_{3}$ are used to evaluate $\mathrm{H} 1(\mathrm{~b})$.

To test $\mathrm{H} 2(\mathrm{a}), \mathrm{H} 2(\mathrm{~b})$ and $\mathrm{H} 2$ (c) (the interaction effect of review attributes with reviewer profile image), we examine: 


$$
\begin{aligned}
\text { LnHelp }_{\text {ip }}=C & +\alpha_{1} \cdot \text { Image }_{i p}+\alpha_{4} \cdot \text { Image }_{i p} \cdot \text { LnLength }_{i p}+\alpha_{5} \cdot \text { Image }_{i p} \cdot \text { LnRating }_{i p} \\
& +\alpha_{6} \cdot \text { Image }_{i p} \cdot \text { Equivocality }_{i p}++\beta_{1} \cdot \text { LnLength }_{i p}+\beta_{2} \cdot \text { LnRating }_{i p} \\
& +\beta_{3} \cdot \text { Equivocality }_{i p}+\beta_{4} \cdot \text { LnAverage }_{p}+\beta_{5} \cdot \text { LnReview }_{p}+\beta_{6} \\
& \cdot \text { Gender }_{i p}+\beta_{7} \cdot \text { Name }_{i p}+\varepsilon_{i p}
\end{aligned}
$$

The estimations of $\alpha_{4}, \alpha_{5}$ and $\alpha_{6}$ are used to evaluate $\mathrm{H} 2(\mathrm{a}), \mathrm{H} 2(\mathrm{~b})$ and $\mathrm{H} 2(\mathrm{c})$, respectively.

\section{Results and discussion}

Table 3 reports the descriptive statistics, including mean and standard deviation for all variables and their Pearson correlation coefficients. As illustrated in Table 3, thirty-five percent of reviews in our sample contain reviewer profile image. The average review length of our sample is 25.74 words. The average rating is 2.84 . The average of Equivocality ip $_{\text {in }} .12$, indicating that about $12 \%$ of review ratings are of the value 3 . There were thirty-six percent female and sixty-four percent male reviewers. A large portion of reviewers (84\%) use legitimate names.

\section{[Insert Table 3 Here]}

We performed several diagnostic checks to ascertain the stability of our analysis and results. As a result, we accounted for heteroscedastic error distribution and calculated heteroscedasticityconsistent standard errors for all of our models [21]. Table 4 reports the heteroscedasticity-consistent regression results. We estimated eight models: model 1 is based on equation 1 to test H1(a), models 2, 3, and 4 are based on equation 2 to test H1(b), and models 5 to 8 are associated with equation 3 to test H2(a), H2(b) and H2(c). All models achieve a good fit with adjusted R squared values ranging from .32 to .38 . The maximum variance inflation factors (VIF) range from 4.11 to 9.59 , below the cut-off value of 10 [26]. Multicollinearity is not a concern.

[Insert Table 4 Here] 
Our results suggest that reviewer profile image, but not image type, is an important factor determining review helpfulness. Shown in model 1 and all other models with additional variables, the relationship between Image $_{i p}$ and Help ip $_{\text {is }}$ significantly negative. Because Help ip $_{\text {in }}$ is reverse measure for review helpfulness, this result indicates that reviewer profile image enhances review helpfulness. H1(a) is strongly supported. The effects of image types are tested in models 2, 3, and 4. Models 2 and 3 test the potential additive effect of self-image and family-image separately, and model 4 includes both image types. The estimations of Self Image $e_{i p}$ in models 2 and 4 are consistently negative but insignificant. The estimations of FamilyImage ip $_{\text {in }}$ models 3 and 4 are consistently positive but insignificant. This indicates that image type has little differential effect. Self-image does not significantly differ from other image types in enhancing review helpfulness. H1(b) is not supported.

Consistent with previous research [16, 34, 37], our results indicate that review attributes including review length, ratings, and equivocality are significant factors affecting review helpfulness. Shown in all models, the relationship between Leng $_{t} h_{i p}$ and Help $p_{i p}$ is significantly negative. This shows that the review length enhances review helpfulness. The significant negative estimation of Rating $_{\text {ip }}$ indicates a positive relationship between rating valence and review helpfulness. This result is consistent with that of previous study [37]. The association of Equivocality ip $_{\text {with }}$ Help $_{i p}$ is significantly positive, demonstrating that review equivocality reduces review helpfulness.

$\mathrm{H} 2(\mathrm{a}), \mathrm{H} 2(\mathrm{~b})$ and $\mathrm{H} 2(\mathrm{c})$, i.e. the interaction effect of reviewer profile image with review attributes, are tested separately under models 5 to 7 . To determine whether the findings hold when they are jointly tested, we pool all interaction terms in model 8 (Table 4). Inferences drawn from models 5 to 7 are consistent with that from model 8 . The parameter estimation of the interaction term $\operatorname{Image}_{i p}$. LnLengthg $_{i p}$ in models 5 and 8 are significantly negative, indicating that review length moderates the effect of reviewer profile image on review helpfulness. The effect of reviewer profile image on review helpfulness is stronger for longer reviews than shorter ones. H2(a) is supported. In models 6, 7, and 8, 
the parameter estimations of the interaction terms $\operatorname{Image}_{i p} \cdot \operatorname{LnRating}_{i p}$ and $\operatorname{Image}_{i p}$. Equivocality $_{i p}$ are not significant, indicating that the effect of reviewer profile image on review helpfulness is not moderated by review valence and equivocality. $\mathrm{H} 2(\mathrm{~b})$ and $\mathrm{H} 2(\mathrm{c})$ are not supported.

We performed various robustness checks to verify our findings. For example, to test whether the relationship between reviewer profile image and perceived review helpfulness varies for different products (paid vs. free or popular vs. unpopular apps), sub-samples based on product characteristics were created. We also created two sub-samples to test whether sampling the top 1,500 helpful reviews, when a large number of reviews are available, introduces bias in our results. One subsample included reviews from the four less popular gaming apps, representing the entire review sequences, and the other consisted of reviews from the five more popular gaming apps, covering the 1,500 most helpful reviews (with the exception of 2,500 reviews for Candy Crush Sage). Analysis was conducted using these sub-samples of reviews. No major difference was identified and main effects remained the same.

\section{Conclusions}

Online reviews have received a considerable interest from researchers [28], but very few have investigated the impact of images on online review helpfulness. This research aims to examine the importance of reviewer profile image and understand the way it affects consumer evaluation of review helpfulness. After controlling for review attributes, we have shown that the presence of reviewer profile image enhances consumer's perceived value of an online review.

To explain the nature of such influence, we consider two functions for reviewer profile image based on information systems, psychology and individual learning literature: 1) the decorative function of reviewer profile image that adds to the value of a review by attracting attention and creating affective responses; and 2) the information function of reviewer self-image that provides 
reviewer identity information. Results indicate that the differential effect of image types is insignificant and all images have a similar influence on the perceived helpfulness of a review. Reviewer self-image, the only image type associated with reviewer identity disclosure, does not differ from other types of images in enhancing perceived review helpfulness. Therefore, the impact of information function of self-image is not significant in our sample. Reviewer profile image contributes to perceived review helpfulness mainly through its decorative function.

Our findings in relation to review attributes are largely consistent with previous research [19, 34, 37]. Helpful reviews tend to be longer, less equivocal, and more positive. We have tested the potential interaction effect of review attribute and reviewer profile image. Results show that the relationship between reviewer profile image and perceived review helpfulness is moderated by review length, but not review valence and equivocality. As expected, the impact of reviewer profile image is stronger for longer reviews compared with shorter ones.

\subsection{Theoretical and managerial implications}

This paper has a number of theoretical and managerial contributions. Our results add to the empirical research on online review helpfulness. To our knowledge, this research is the first to introduce and systematically examine the role of reviewer profile image in enhancing review helpfulness. It explains the impact of reviewer profile image by exploring its two potential functions and interaction effect with review attributes. Different from prior studies that only consider the information function of reviewer self-image, our results from cross-image-type analysis illustrate the importance of reviewer profile image in providing aesthetic appeal (the decorative function). Our findings contribute to the decision-making literature in several ways. Drawing on IS, information processing, marketing and individual learning theories, it enriches our understanding of attributes that affect consumer evaluation of reviews. It stresses the importance of images in information processing and perception of information helpfulness. It also highlights the potentials of decorative 
images, unrelated to the content, in meeting information requirements of users, simplifying comprehension of content and enhancing decision making, particularly when large amount of textual information is presented. The two functions of visual elements can be applied to information processing in other contexts.

This paper is one of the very first studies in this line of research that draws data from mobile applications product category. Prior research on review helpfulness has been mainly based on data collected from Amazon.com. A new product category not only enriches the sample variety, but is also necessary to enable generalization of suggested theories. Mobile application is a fast moving market with its value being estimated above US\$50 billion in 2013 [19]. This is an important product category which is highly influenced by online reviews.

Our findings also have interesting implications for retailers and review platforms that aim to offer helpful content. By understanding the type of information that consumers desire and find useful, retailers can be more efficient in their communications and improve the design of their retail environment and review systems. For example, many online review platforms have not been designed to allocate a space to reviewer profile image. Although this allows display of an optimal number of reviews on the screen, we suggest that images can play an important role in the way review content is read, perceived, and processed. In light of our results and also advances in image mining techniques, review systems should capitalize on promoting reviewer profile images. We found that presence of reviewer profile image, with no differentiation among image types, results in higher perceived helpfulness of a review. These platforms can therefore encourage reviewers, particularly those who tend to write relevant and accurate reviews, to post an image of their choice. Images could also be treated as an added variable to rank and display reviews with similar helpfulness votes. The results of this research can be utilized to develop better decision support systems that provide more selective information and enhance decision-making. A more sophisticated application of this concept could be extended to product recommender systems to automatically pull 
out the suggestions made by helpful reviews. Furthermore, recognizing influential reviews can help retailers predict the market and even adapt their product features. Finally, by identifying the content that is more likely to be ranked as helpful, businesses can act in a proactive and timely manner to address any undesired issue. This can be particularly of great interest in platforms where they can reply to each individual customer review.

\subsection{Limitations and further research}

This research has several limitations and suggests further research directions. First, out of various reviewer attributes that are displayed in different review websites, we have focused on reviewer profile image. While this focus allowed us to explore the effect of reviewer profile image at the image-type level and consider its interaction effects, it limits our ability to explore and compare inter-relationships among reviewer attributes. Future research can examine other reviewer attributes and explore their inter-relationship.

This research did not find any evidence for the differential effect of various types of images and therefore does not support the additional effect of reviewer self-image on perceived review helpfulness at an aggregate level. There are two possible explanations for this result. First, online users may not consider reviewer self-images as substantive identity information, possibly due to the small image size, vague personal feature, and lack of verification. In this case, literature suggesting the use of reviewer self-image as a component/measure of reviewer identity information [24, 33] is challenged. Second, if the self-image is considered as reviewer identity information, then either the identity information is not valued by readers in their evaluation of review helpfulness, or reviewers with different identities are favored by different readers but the aggregate level analysis cannot 
capture the effect of homophily ${ }^{2}$. Therefore, caution needs to be exercised in interpreting and applying our conclusion that is at an aggregate level.

Replication studies are called for in order to verify the results of this study. While the results are grounded on a solid theoretical foundation drawn from the information systems, information processing, psychology and individual learning literature, this study is among the first to examine the effect of reviewer profile image. The empirical findings are based on mobile gaming applications, which are different from common consumer goods. Therefore, replication studies in different contexts are necessary to enable the generalizability of our findings and further explore potential differences among various product categories. Actual review data from online platforms has been used to ensure ecological validity of the research findings. Future research can use lab experiments and eye tracking techniques to understand the nature of visual effects in more depth. In addition, this research employs review helpfulness ranking based on reader votes to measure review helpfulness. Future research could use review helpfulness vote counts to explore the effect of reviewer profile image and compare performance of the two measures.

\section{References}

[1] H. Baek, J. Ahn, Y. Choi, Helpfulness of online consumer reviews: Readers' objectives and review cues, International Journal of Electronic Commerce 17 (2) (2012) 99-126.

[2] S. Basuroy, S. Chatterjee, S.A. Ravid, How critical are critical reviews? The box office effects of film critics, star power, and budgets, Journal of Marketing 67 (4) (2003) 103-117.

[3] Q. Cao, W. Duan, Q. Gan, Exploring determinants of voting for the "helpfulness" of online user reviews: A text mining approach, Decision Support Systems 50 (2) (2011) 511-521.

\footnotetext{
${ }^{2}$ We thank the anonymous reviewer who points this out.
} 
[4] H.N. Chen, C.Y. Huang, An investigation into online reviewers' behavior, European Journal of Marketing 47 (10) (2013) 1758-1773.

[5] C.M. Cheung, M.K. Lee, N. Rabjohn., The impact of electronic word-of-mouth: The adoption of online opinions in online customer communities, Internet Research 18 (3) (2008) 229-247.

[6] J.A. Chevalier, D. Mayzlin, The effect of word of mouth on sales: Online book reviews, Journal of Marketing Research 43 (3) (2006) 345-354.

[7] T. Christiansen, S.S. Tax, Measuring word of mouth: the questions of who and when? Journal of Marketing Communications 6 (3) (2000) 185-199.

[8] G. Cui, H.-K. Lui, X. Guo,. The effect of online consumer reviews on new product sales, International Journal of Electronic Commerce 17 (1) (2012) 39-58.

[9] D. Cyr, K. Hassanein, M. Head, A. Ivanov, The role of social presence in establishing loyalty in e-service environments, Interacting with Computers 19 (1) (2007) 43-56.

[10] D. Cyr, M. Head, H. Larios, B. Pan, Exploring human images in website design: a multi-method approach, Management Information Systems Quarterly 33 (3) (2009) 539-566.

[11] C. Dellarocas, X.M. Zhang, N.F. Awad, Exploring the value of online product reviews in forecasting sales: The case of motion pictures, Journal of Interactive Marketing 21 (4) (2007) $23-45$.

[12] R. Dhar, K. Wertenbroch, Consumer choice between hedonic and utilitarian goods, Journal of Marketing Research 37 (1) (2000) 60-71.

[13] W. Duan, B. Gu, A.B. Whinston, Do online reviews matter? An empirical investigation of panel data, Decision Support Systems 45 (4) (2008) 1007-1016.

[14] R. Filieri, What makes online reviews helpful? A diagnosticity-adoption framework to explain informational and normative influences in e-WOM, Journal of Business Research 68 (6) (2015) 1261-1270.

[15] K. Floyd, R. Freling, S. Alhoqail, H.Y. Cho, T. Freling, How online product reviews affect retail 
sales: A meta-analysis, Journal of Retailing 90 (2) (2014) 217-232.

[16] C. Forman, A. Ghose, B. Wiesenfeld, Examining the relationship between reviews and sales: The role of reviewer identity disclosure in electronic markets, Information Systems Research 19 (3) (2008) 291-313.

[17] J. J. Garrett, Elements of User Experience, The: User-Centered Design for the Web and Beyond: Pearson Education, 2010.

[18] D. Gefen, D.W. Straub, Managing user trust in B2C e-services, E-service Journal 2 (2) (2003) 724.

[19] A. Ghose, S.P. Han, Estimating demand for mobile applications in the new economy, Management Science 60 (6) (2014) 1470-1488.

[20] R. Govers, F.M. Go, Projected destination image online: Website content analysis of pictures and text, Information Technology and Tourism 7 (2) (2004) 73-89.

[21] W. H. Greens, Econometric Analysis (4 ${ }^{\text {th }}$ ed.), Upper Saddle River, NJ: Prentice Hall, 2000.

[22] P. Gupta, J. Harris, How e-WOM recommendations influence product consideration and quality of choice: a motivation to process information perspective, Journal of Business Research 63 (9) (2010) 1041-1049.

[23] A. H. Huang, K. Chen, D.C. Yen, T.P. Tran, A study of factors that contribute to online review helpfulness, Computers in Human Behavior 48 (2015) 17-27.

[24] Z. Jiang, I. Benbasat, Research note-investigating the influence of the functional mechanisms of online product presentations, Information Systems Research 18 (4) (2007) 454-470.

[25] F.R. Jiménez, N.A. Mendoza, Too popular to ignore: The influence of online reviews on purchase intentions of search and experience products, Journal of Interactive Marketing 27 (3) (2013) 226-235.

[26] G.G. Judge, R.C. Hill, W.E. Griffiths, H. Lutkepohl, T.C. Lee, Introduction to the Theory and Practice of Econometrics, John Wiley and Sons, New York, 1988. 
[27] D.E. Kanouse, L.R. Hanson, Negativity in Evaluations. Morristown, NJ: General Learning Press, 1972.

[28] R.A. King, P. Racherla, V.D. Bush, What we know and don't know about online word-ofmouth: A review and synthesis of the literature, Journal of Interactive Marketing 28 (3) (2014) 167-183.

[29] J. Lee, D.H. Park, I. Han, The effect of negative online consumer reviews on product attitude: An information processing view, Electronic Commerce Research and Applications 7 (3) (2008) 341-352.

[30] A. Lenzner, W. Schnotz, A. Müller, The role of decorative pictures in learning. Instructional Science 41 (5) (2013) 811-831.

[31] M. Li, L. Huang, C.-H. Tan, K.-K. Wei, Helpfulness of online reviews as seen by consumers: Source and content features, International Journal of Electronic Commerce 17 (4) (2013) 101136.

[32] M. Ma, R. Agarwal, Through a glass darkly: Information technology design, identity verification, and knowledge contribution in online communities, Information Systems Research 18 (1) (2007) 42-67.

[33] J.E. Maddux, R.W. Rogers, Effects of source expertness, physical attractiveness, and supporting arguments on persuasion: A case of brains over beauty, Journal of Personality and Social Psychology 39 (2) (1980) 235-244.

[34] S.M. Mudambi, D. Schuff, What makes a helpful online review? A study of customer reviews on Amazon.com, Management Information Systems Quarterly 34 (1) (2010) 185-200.

[35] T. Ngo-Ye, A. P. Sinha, The influence of reviewer engagement characteristics on online review helpfulness: A text regression model, Decision Support Systems 61 (2014) 47-58.

[36] H. Northdurft, Salience effects across dimensions in visual search, Vision Research 33 (5-6) (1993) 839-844. 
[37] Y. Pan, J.Q. Zhang, Born unequal: a study of the helpfulness of user-generated product reviews, Journal of Retailing 87 (4) (2011) 598-612.

[38] C. Park, T.M. Lee, Information direction, website reputation and eWOM effect: A moderating role of product type, Journal of Business Research 62 (1) (2009) 61-67.

[39] D.H. Park, J. Lee, I. Han, The effect of on-line consumer reviews on consumer purchasing intention: The moderating role of involvement, International Journal of Electronic Commerce 11 (4) (2007) 125-148.

[40] N. Purnawirawan, P. De Pelsmacker, N. Dens, Balance and sequence in online reviews: How perceived usefulness affects attitudes and intentions, Journal of Interactive Marketing 26 (4) (2012) 244-255.

[41] A. Qazi, K.B.S. Syed, R.G. Raj, E. Cambria, M. Tahir, D. Alghazzawi, A concept-level approach to the analysis of online review helpfulness, Computers in Human Behavior 58 (2016), $75-81$.

[42] L. Qiu, J. Pang, K.H. Lim, Effects of conflicting aggregated rating on eWOM review credibility and diagnosticity: The moderating role of review valence, Decision Support Systems 54 (1) (2012) 631-643.

[43] P. Racherla, W. Friske, Perceived 'usefulness' of online consumer reviews: An exploratory investigation across three services categories, Electronic Commerce Research and Applications $11(6)(2012)$ 548-559.

[44] K. Rayner, C. M. Rotello, A.J. Stewart, J. Keir, S.A. Duffy, Integrating text and pictorial information: eye movements when looking at print advertisements, Journal of Experimental Psychology: Applied 7(3) (2001) 219-226.

[45] Y. Ren, R. Kraut, S. Kiesler, Applying common identity and bond theory to design of online communities, Organization Studies 28 (3) (2007) 377-408. 
[46] J.R. Rossiter, L. Percy, Visual imaging ability as a mediator of advertising response, Advances in Consumer Research 5 (1) (1978) 621-629.

[47] M. Salehan, D.J. Kim, Predicting the performance of online consumer review: A sentiment mining approach to big data analytics, Decision Support Systems 81 (2016) 30-40.

[48] C.A. Sanchez, J. Wiley, An examination of the seductive details effect in terms of working memory capacity, Memory \& Cognition 34 (2) (2006) 344-355.

[49] N. Schwarz, Feelings as information: informational and motivational functions of affective states. Guilford Press, 1990.

[50] L.M. Scott, Images in advertising: The need for a theory of visual rhetoric, Journal of Consumer Research 21 (2) (1994) 252-273.

[51] S. Sontag, On Photography, Penguin Classics London England, 2002.

[52] J. Steuer, Defining virtual reality: Dimensions determining telepresence, Journal of Communication 42 (4) (1992) 73-93.

[53] S. Tahahashi, Aesthetic properties of pictuorial perception, Psychological Review 102 (4) 671683.

[54] L.C. Tidwell, J.B. Walther, Computer mediated communication effects on disclosure, impressions, and interpersonal evaluations: Getting to know one another a bit at a time, Human Communication Research 28 (3) (2002) 317-348.

[55] G. Underwood, Eye fixations on pictures of natural scenes: Getting the gist and identifying the components, Cognitive Processes in Eye Guidance (2005) 163-187.

[56] G. Underwood, L. Jebbett, K. Roberts, Inspecting pictures for information to verify a sentence: Eye movements in general encoding and in focused search, Quarterly Journal of Experimental Psychology Section A 57 (1) (2004) 165-182.

[57] A.H.C. Van der Heijden, Selective Attention in Vision. Rougledge, New York, 1992.

[58] R. Vasa, L. Hoon, K. Mouzakis, A. Noguchi, A preliminary analysis of mobile app user reviews, 
The Proceedings of the 24th Australian Computer-Human Interaction Conference (2012).

[59] J.B. Walther, Computer-mediated communication: Impersonal, interpersonal, and hyperpersonal interaction, Communication Research 23 (1) (1996) 3-44.

[60] W. Wang, L. Qiu, D. Kim, Izk Benbasat, Effects of rational and social appeals of online recommendation agents on cognition- and affect-based trust, Decision Support Systems 86 (2016) 48-60.

[61] Z. Wang, H. Li, Q. Ye, R. Law, Saliency effects of online reviews embedded in the description on sales: Moderating role of reputation, Decision Support Systems 87 (2016) 50-58.

[62] D. Weathers, S. D. Swain, V. Grover, Can online product reviews be more helpful? Examining characteristics of information content by product type, Decision Support Systems 79 (2015) 1223.

[63] D. Yin, S. Bond, H. Zhang, Anxious or angry? Effects of discrete emotions on the perceived helpfulness of online reviews, MIS Quarterly 38 (2) (2014) 539-560.

[64] Y. Yoo, M. Alavi, Media and group cohesion: Relative influences on social presence, task participation, and group consensus, MIS Quarterly 25 (3) (2001) 371-390.

[65] F. Zhu, X. Zhang, Impact of online consumer reviews on sales: The moderating role of product and consumer characteristics, Journal of Marketing 74 (2) (2010) 133-148.

[66] L. Zhu, G. Yin, W. He, Is this opinion leader's review useful? Peripheral cues for online review helpfulness, Journal of Electronic Commerce Research 15 (4) (2014) 267-280. 
Figure 1. Research Framework

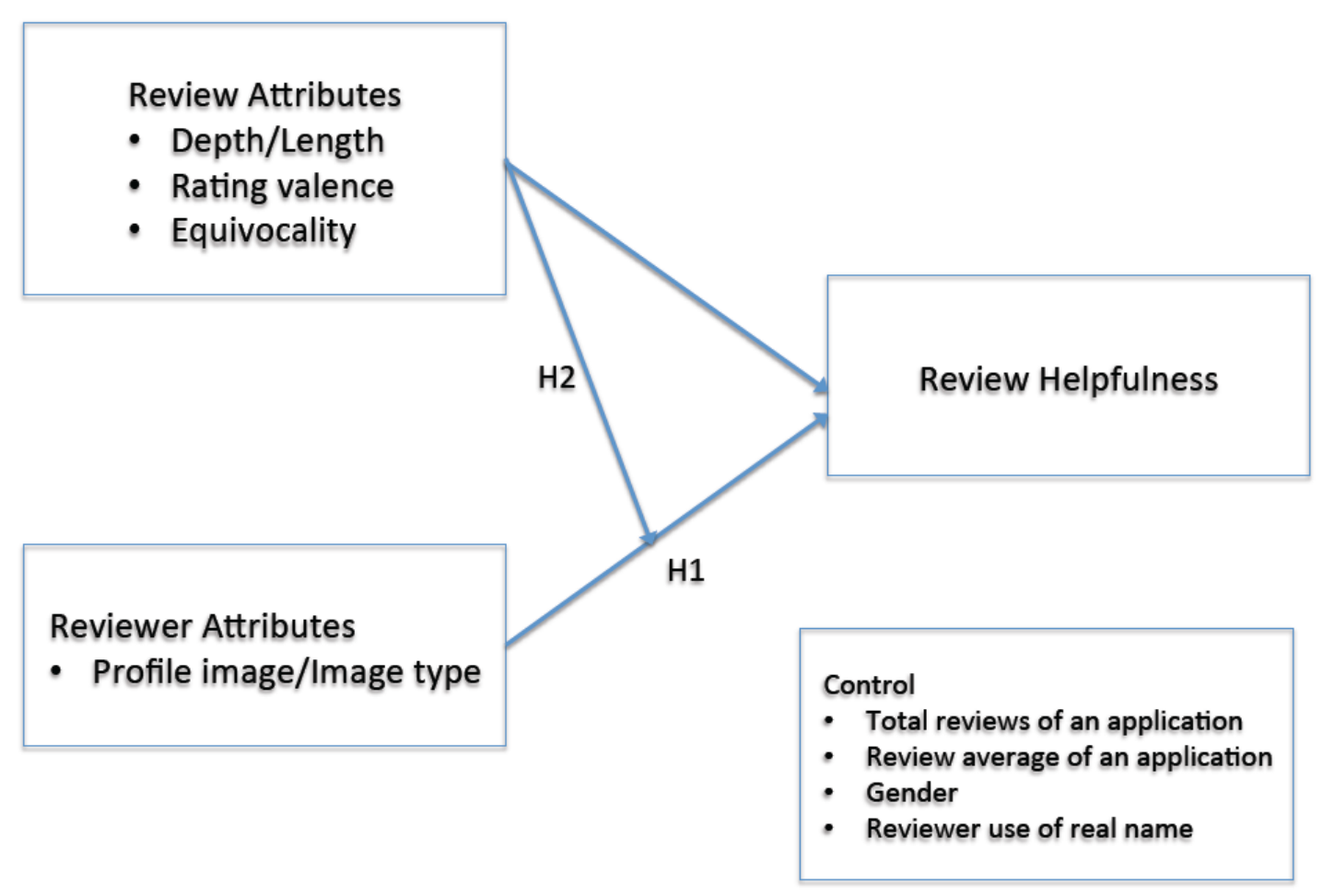

Figure 2. Sample reviews from play.google.com

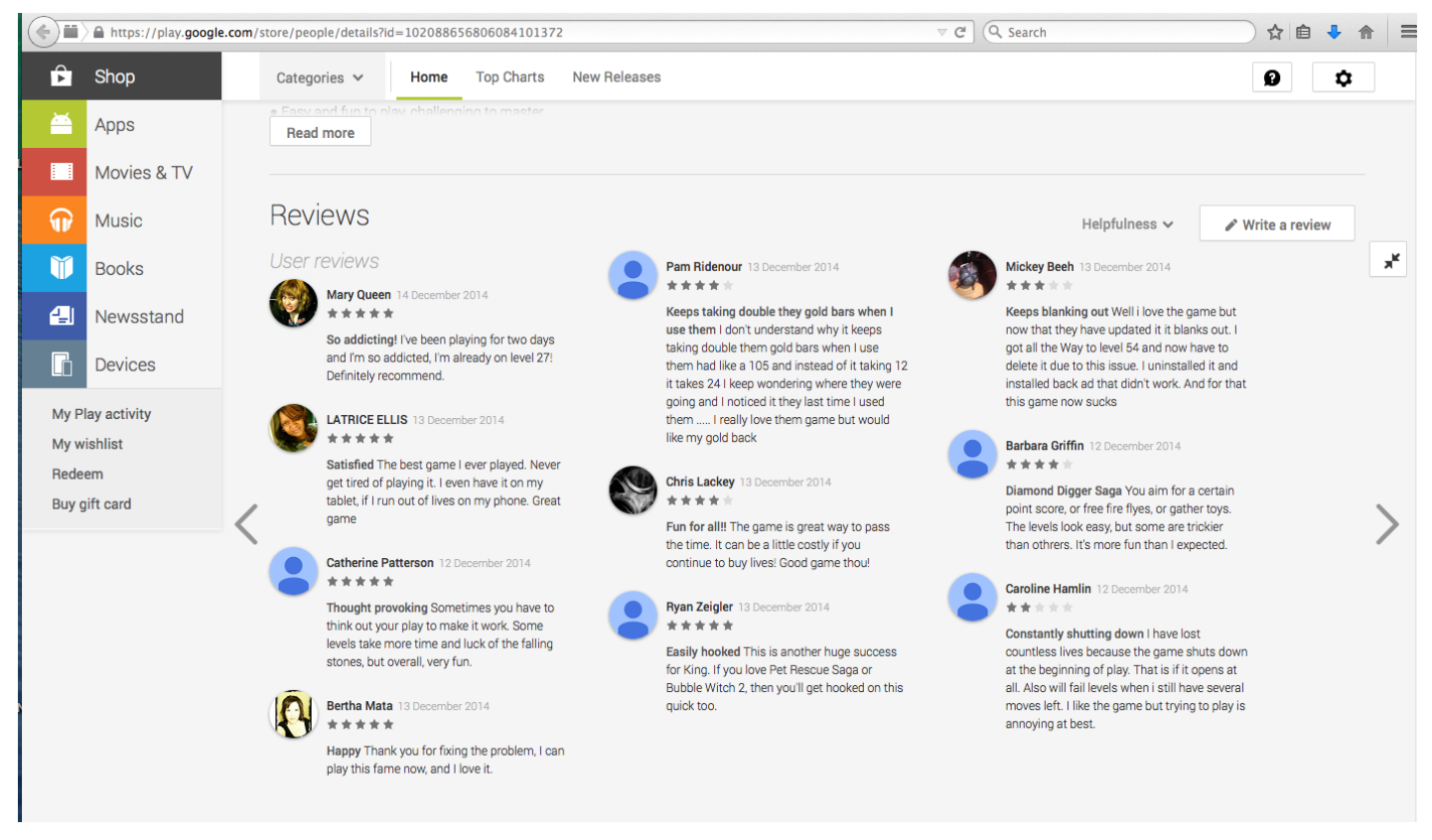


Table 1 Summary of Key Empirical Studies on Factors Contributing to Review Helpfulness

\begin{tabular}{|c|c|c|c|c|c|}
\hline \multirow[b]{2}{*}{ Studies } & \multirow[b]{2}{*}{ Data Source } & \multirow{2}{*}{$\begin{array}{c}\text { Measure for } \\
\text { Review } \\
\text { Helpfulness }\end{array}$} & \multicolumn{2}{|c|}{ Contributing Factors Examined } & \multirow[b]{2}{*}{ Findings } \\
\hline & & & Review attributes & $\begin{array}{l}\text { Reviewer } \\
\text { attributes }\end{array}$ & \\
\hline$[1]$ & Amazon.com & $\begin{array}{l}\text { Percentage of } \\
\text { helpful votes } \\
\text { in total votes } \\
\text { for a review }\end{array}$ & $\begin{array}{l}\text { - Rating } \\
\text { inconsistency } \\
\text { - Review length } \\
\text { - Negative word }\end{array}$ & $\begin{array}{l}\text { - Reviewer ranking } \\
\text { - Reviewer real } \\
\text { name }\end{array}$ & $\begin{array}{l}\text { - Both peripheral cues, including review rating and } \\
\text { reviewer credibility, and central cues, such as review } \\
\text { content, influence review helpfulness. }\end{array}$ \\
\hline$[3]$ & Amazon.com & $\begin{array}{l}\text { Percentage of } \\
\text { helpful votes } \\
\text { in total votes } \\
\text { for a review }\end{array}$ & - Review length & $\begin{array}{l}\text { - Reviewer } \\
\text { experience } \\
\text { - Reviewer impact } \\
\text { - Reviewer } \\
\text { cumulative } \\
\text { helpfulness }\end{array}$ & $\begin{array}{l}\text { - Review length, when shorter than average, has a } \\
\text { positive effect on review helpfulness. } \\
\text { - Reviewer cumulative helpfulness influences review } \\
\text { helpfulness. } \\
\text { - Reviewer experience and reviewer impact do not } \\
\text { have an effect on review helpfulness. }\end{array}$ \\
\hline$[16]$ & Amazon.com & $\begin{array}{l}\text { Percentage of } \\
\text { helpful votes } \\
\text { in total votes } \\
\text { for a review }\end{array}$ & $\begin{array}{l}\text { - Review } \\
\text { equivocality }\end{array}$ & $\begin{array}{l}\text { - Reviewer identity } \\
\text { disclosure }\end{array}$ & $\begin{array}{l}\text { - Both review equivocality and reviewer identity } \\
\text { influence review helpfulness. } \\
\text { - Review equivocality and reviewer identity have } \\
\text { interaction effect on review helpfulness. }\end{array}$ \\
\hline$[34]$ & Amazon.com & $\begin{array}{l}\text { Percentage of } \\
\text { helpful votes } \\
\text { in total votes } \\
\text { for a review }\end{array}$ & $\begin{array}{l}\text { - Review extremity } \\
\text { - Review length }\end{array}$ & & $\begin{array}{l}\text { - Review extremity and depth positively influence } \\
\text { review helpfulness. } \\
\text { - Product types (search vs. experience goods) } \\
\text { moderate the effect of review extremity on review } \\
\text { helpfulness. }\end{array}$ \\
\hline$[35]$ & $\begin{array}{l}\text { Yelp.com and } \\
\text { Amazon.com }\end{array}$ & $\begin{array}{l}\text { Number of } \\
\text { 'useful' votes }\end{array}$ & $\begin{array}{l}\text { - Review text } \\
\text { content }\end{array}$ & $\begin{array}{l}\text { - Reviewer } \\
\text { engagement }\end{array}$ & $\begin{array}{l}\text { - Both review text content and reviewer engagement } \\
\text { characteristics predict review helpfulness. }\end{array}$ \\
\hline$[37]$ & Amazon.com & $\begin{array}{l}\text { Percentage of } \\
\text { helpful votes } \\
\text { in total votes } \\
\text { for a review }\end{array}$ & $\begin{array}{l}\text { - Review length } \\
\text { - Rating valence }\end{array}$ & $\begin{array}{l}\text { - Reviewer } \\
\text { innovativeness as } \\
\text { revealed in review } \\
\text { content }\end{array}$ & $\begin{array}{l}\text { - Review length and rating valence positively affect } \\
\text { review helpfulness. } \\
\text { - Product types (experiential vs. utilitarian products) } \\
\text { moderate the effect. } \\
\text { - A curvilinear relationship exists between expressed } \\
\text { reviewer innovativeness and review helpfulness. }\end{array}$ \\
\hline$[41]$ & $\begin{array}{l}\text { TripAdvisor.c } \\
\text { om }\end{array}$ & $\begin{array}{l}\text { Number of } \\
\text { helpfulness } \\
\text { votes }\end{array}$ & $\begin{array}{l}\text { - Review type } \\
\text { - Review length } \\
\text { - Average length of } \\
\text { review sentence }\end{array}$ & $\begin{array}{l}\text { - Reviewer } \\
\text { helpfulness }\end{array}$ & $\begin{array}{l}\text { - Review length and average review sentence length } \\
\text { affect review helpfulness. } \\
\text { - Relationship between length and review helpfulness } \\
\text { varies based on the review type. }\end{array}$ \\
\hline
\end{tabular}




\begin{tabular}{|c|c|c|c|c|c|}
\hline$[43]$ & Yelp.com & $\begin{array}{l}\text { Number of } \\
\text { 'useful' votes }\end{array}$ & $\begin{array}{l}\text { - Review length } \\
\text { - Rating valence } \\
\text { - Review } \\
\text { equivocality }\end{array}$ & $\begin{array}{l}\text { - Reviewer identity } \\
\text { disclosure } \\
\text { - Reviewer } \\
\text { expertise } \\
\text { - Reviewer } \\
\text { reputation } \\
\end{array}$ & $\begin{array}{l}\text { - Mixed support to the effects of various review and } \\
\text { reviewer attributes to review usefulness. } \\
\text { - Mixed results on the differential effects of review } \\
\text { and reviewer attributes on review usefulness among } \\
\text { search, experience, and credence services categories. }\end{array}$ \\
\hline$[47]$ & Amazon.com & $\begin{array}{l}\text { Percentage of } \\
\text { helpful votes } \\
\text { in total votes } \\
\text { for a review }\end{array}$ & $\begin{array}{l}\text { - Review length } \\
\text { - Review sentiment } \\
\text { - Review polarity }\end{array}$ & & $\begin{array}{l}\text { - Review length positively influences review } \\
\text { helpfulness. } \\
\text { - Review sentiment negatively influences review } \\
\text { helpfulness. } \\
\text { - Review polarity moderates the impact of sentiment } \\
\text { on review helpfulness. }\end{array}$ \\
\hline$[62]$ & Amazon.com & $\begin{array}{l}\text { Percentage of } \\
\text { helpful votes } \\
\text { in total votes } \\
\text { for a review }\end{array}$ & $\begin{array}{l}\text { - Information } \\
\text { balance } \\
\text { - Claimed expertise } \\
\text { - Reference to other } \\
\text { brands or reviews } \\
\text { - Description of } \\
\text { usage situations } \\
\text { - Listing product } \\
\text { features }\end{array}$ & & - Review content affect helpfulness. \\
\hline$[66]$ & Yelp.com & $\begin{array}{l}\text { Number of } \\
\text { 'useful' votes }\end{array}$ & $\begin{array}{l}\text { - Review rating } \\
\text { extremity }\end{array}$ & $\begin{array}{l}\text { - Reviewer } \\
\text { expertise } \\
\text { - Reviewer online } \\
\text { attractiveness }\end{array}$ & $\begin{array}{l}\text { - Reviewer expertise and reviewer online } \\
\text { attractiveness positively affect review helpfulness. } \\
\text { - Rating extremity moderates the influence of } \\
\text { reviewer expertise and reviewer online attractiveness. }\end{array}$ \\
\hline $\begin{array}{l}\text { This } \\
\text { research }\end{array}$ & $\begin{array}{l}\text { Play.google.co } \\
\mathrm{m}\end{array}$ & $\begin{array}{l}\text { Helpfulness } \\
\text { vote ranking } \\
\text { (a reverse } \\
\text { measure) }\end{array}$ & $\begin{array}{l}\text { - Review length } \\
\text { - Rating valence } \\
\text { - Review } \\
\text { equivocality }\end{array}$ & $\begin{array}{l}\text { - Reviewer profile } \\
\text { image/type }\end{array}$ & $\begin{array}{l}\text { - Review attributes, i.e. length, valence, and } \\
\text { equivocality, affect review helpfulness. } \\
\text { - Reviewer profile image enhances review } \\
\text { helpfulness. } \\
\text { - No differential effects among various reviewer } \\
\text { profile image types are found. } \\
\text { - The effect of reviewer profile image on review } \\
\text { helpfulness is moderated by review length, but not by } \\
\text { review valence and equivocality. }\end{array}$ \\
\hline
\end{tabular}


Table 2 Games in the sample

\begin{tabular}{|c|c|c|c|c|c|}
\hline Games & Total installs & Price & $\begin{array}{c}\text { Average } \\
\text { rating }\end{array}$ & $\begin{array}{c}\text { Total } \\
\text { reviews }\end{array}$ & $\begin{array}{l}\text { Number of } \\
\text { reviews } \\
\text { collected* }\end{array}$ \\
\hline $\begin{array}{l}\text { Candy Crush } \\
\text { Sage }\end{array}$ & $\begin{array}{l}\text { 100mil - } \\
500 \mathrm{mil}\end{array}$ & free & 4.3 & $10,536,000$ & $500 * *$ \\
\hline $\begin{array}{l}\text { Crazy Craft } 3 \\
\text { for Minecraft }\end{array}$ & $\begin{array}{c}10,000- \\
50,000\end{array}$ & $\$ 2.35$ & 2.2 & 597 & $92 * * *$ \\
\hline $\begin{array}{c}\text { Diamond } \\
\text { Digger }\end{array}$ & $10 \mathrm{mil}-50 \mathrm{mil}$ & free & 4.2 & 659,000 & 300 \\
\hline $\begin{array}{c}\text { FIFA } 15 \\
\text { Ultimate Team }\end{array}$ & $10 \mathrm{mil}-50 \mathrm{mil}$ & free & 4.3 & $2,074,000$ & 300 \\
\hline $\begin{array}{c}\text { Invisible Skins } \\
\text { for Slitherio }\end{array}$ & $\begin{array}{c}10,000- \\
50,000 \\
\end{array}$ & free & 2.1 & 1,615 & 300 \\
\hline Minecraft & $5 \mathrm{mil}-10 \mathrm{mil}$ & $\$ 6.99$ & 4.5 & 743,000 & 300 \\
\hline NBA 2 K16 & $\begin{array}{c}10,000- \\
50,000\end{array}$ & $\$ 9.99$ & 3.4 & 7,672 & 300 \\
\hline $\begin{array}{c}\text { PAW Patrol: } \\
\text { Rescue Run HD }\end{array}$ & $\begin{array}{c}10,000- \\
50,000\end{array}$ & $\$ 7.82$ & 3.5 & 359 & $27 * * *$ \\
\hline Teeny Titans & $\begin{array}{c}10,000- \\
50,000\end{array}$ & $\$ 4.99$ & 4.5 & 2,810 & $59 * * *$ \\
\hline
\end{tabular}

$*$ We started from the most helpful review of each game and collected every $5^{\text {th }}$ review based on their helpfulness ranking, until three hundred (300) reviews were collected. ** 500 reviews were collected because Candy Crush Sage was by far the most popular game and had a much higher number of installations and reviews compared to others.

*** Less than 300 reviews are collected due to low number of reviews available. Note that reviews with only rating but no content are counted in the total number of reviews, but not shown in the review list of a game, thus unavailable for data collection. For example, while the total review count for Crazy Craft 3 for Minecraft is 597, due to blank-content reviews, actual reviews available are about 460, from which we collected 92 . 
Table 3 Descriptive statistics and correlations of variables

\begin{tabular}{|c|c|c|c|c|c|c|c|c|c|c|}
\hline & $\begin{array}{l}\text { Mean } \\
\text { S.D. }\end{array}$ & $\operatorname{Help}_{i p}$ & Image $_{i p}$ & Length $_{i p}$ & Rating $_{i p}$ & Equivocality $_{i p}$ & Average $_{p}$ & Review $_{p}$ & Gender $_{i p}$ & Name $_{i p}$ \\
\hline Help $_{i p}$ & $\begin{array}{c}164.48 \\
(115.23)\end{array}$ & 1 & & & & & & & & \\
\hline Image $_{i p}$ & $\begin{array}{c}.35 \\
(.48)\end{array}$ & $-.16 * * *$ & 1 & & & & & & & \\
\hline Length $_{i p}$ & $\begin{array}{c}25.74 \\
(22.94)\end{array}$ & $-.27 * * *$ & $.09 * * *$ & 1 & & & & & & \\
\hline Rating $_{i p}$ & $\begin{array}{c}2.84 \\
(1.69)\end{array}$ & $.08^{* * *}$ & $.06^{* * *}$ & $-.09 * * *$ & 1 & & & & & \\
\hline Equivocality $_{i p}$ & $\begin{array}{l}.12 \\
(.32)\end{array}$ & .03 & .03 & $.05 * *$ & $.04 *$ & 1 & & & & \\
\hline Average $_{p}$ & $\begin{array}{l}3.81 \\
(.85)\end{array}$ & $.17 * * *$ & $.08 * * *$ & $.39 * * *$ & $.28 * * *$ & $.12 * * *$ & 1 & & & \\
\hline Review $_{p}$ & $\begin{array}{c}2,736,575 \\
(4,080,248)\end{array}$ & $.42 * * *$ & $-.05 * *$ & .22 & $-.06 * * *$ & -.02 & $.39 * * *$ & 1 & & \\
\hline Gender $_{i p}$ & $\begin{array}{c}.36 \\
(.48)\end{array}$ & $.06^{* * *}$ & .01 & .10 & -.03 & $-.04 *$ & $.09 * * *$ & $.27 * * *$ & 1 & \\
\hline Name $_{i p}$ & $\begin{array}{c}.84 \\
(.16)\end{array}$ & $.05 * *$ & $-.07 * * *$ & $.05 * *$ & $.07 * * *$ & $-.04 *$ & $.12 * * *$ & $.07 * * *$ & $.06 * * *$ & 1 \\
\hline
\end{tabular}


Table 4. Heteroscedasticity-Consistent Regression Results

\begin{tabular}{|c|c|c|c|c|c|c|c|c|}
\hline \multirow{2}{*}{$\begin{array}{l}\text { Equations } \\
\text { Models }\end{array}$} & \multirow{2}{*}{$\begin{array}{c}1 \\
(1)\end{array}$} & \multicolumn{3}{|c|}{2} & \multicolumn{4}{|c|}{3} \\
\hline & & (2) & (3) & $(4)$ & $(5)$ & $(6)$ & $(7)$ & $(8)$ \\
\hline Image $_{i p}$ & $-.28 * * *$ & $-.24 * * *$ & $-.29 * * *$ & $-.25 * * *$ & $-.16^{* *}$ & $-.26 * * *$ & $-.27 * * *$ & $-.16^{* *}$ \\
\hline SelfImage $_{i p}$ & & -.09 & & -.08 & & & & \\
\hline FamilyImage $_{i p}$ & & & .13 & .09 & & & & \\
\hline Image $_{i p} \cdot$ LnLength $_{i p}$ & & & & & $-.08 * *$ & & & $-.07 * *$ \\
\hline Image $_{i p} \cdot$ LnRating $_{i p}$ & & & & & & -.02 & & -.02 \\
\hline Image $_{i p} \cdot$ Equivocality $_{i p}$ & & & & & & & -.06 & -.03 \\
\hline LnLength $_{i p}$ & $-.58 * * *$ & $-.58 * * *$ & $-.58 * * *$ & $-.58 * * *$ & $-.55 * * *$ & $-.58 * * *$ & $-.58 * * *$ & $-.55^{* * *}$ \\
\hline LnRating $_{i p}$ & $-.08 * * *$ & $-.08 * * *$ & $-.08 * * *$ & $-.08 * * *$ & $-.08 * *$ & $-.07 * *$ & $-.08 * * *$ & $-.07 * *$ \\
\hline Equivocality $_{i p}$ & $.21 * * *$ & $.21 * * *$ & $.21 * * *$ & $.22 * * *$ & $.21 * * *$ & $.21 * * *$ & $.24 * * *$ & $.22 * * *$ \\
\hline LnAverage $_{p}$ & $-.90 * * *$ & $-.90 * * *$ & $-.91 * * *$ & $-.91 * * *$ & $-.90 * * *$ & $-.91 * * *$ & $-.90 * * *$ & $-.90 * * *$ \\
\hline LnReview $_{p}$ & $.24 * * *$ & $.24 * * *$ & $.24 * * *$ & $.24 * * *$ & $.24 * * *$ & $.24 * * *$ & $.24 * * *$ & $.24 * * *$ \\
\hline Gender $_{i p}$ & $-.13 * * *$ & $-.13 * * *$ & $-.14 * * *$ & $-.13 * * *$ & $-.13 * * *$ & $-.13 * * *$ & $-.13 * * *$ & $-.13 * * *$ \\
\hline Name $_{i p}$ & .18 & .19 & .18 & .19 & .21 & .18 & .18 & .21 \\
\hline $\mathrm{N}$ & 2,178 & 2,178 & 2,178 & 2,178 & 2,178 & 2,178 & 2,178 & 2,178 \\
\hline Adj. $\mathrm{R}^{2}$ & .32 & .32 & .32 & .32 & .38 & .32 & .32 & .38 \\
\hline Max VIF & 4.11 & 4.11 & 4.11 & 4.11 & 8.73 & 4.10 & 4.11 & 9.59 \\
\hline
\end{tabular}

$* * * \mathrm{p}<.01 ; * * \mathrm{p}<.05 ; * \mathrm{p}<.10$

Note: The DV, review helpfulness ranking is a reverse measure of review helpfulness. 